\title{
Integrated Music and Math Projects in Secondary Education
}

\author{
Miguel R. Wilhelmi ${ }^{1}$ and Mariana Montiel $^{2}$ \\ ${ }^{1}$ Public University of Navarre, 31006 Pamplona-Irunea, Navarra, Spain \\ ${ }^{2}$ Georgia State University, 25 Park Place 1322, Atlanta, GA 30303, USA \\ miguelr.wilhelmi@unavarra.es
}

\begin{abstract}
The introduction of projects involving music and mathematics in Secondary Education should allow the integration of these disciplines by nonspecialists. In the present work we describe an experience carried out with future mathematics teachers with solid scientific-technical training, but little musical training. This pilot contributes with concrete orientations and results para the creation and development of STEAM activities, which can be found in [5].
\end{abstract}

Keywords: STEM, STEAM, Muthsics, Euclidean rhythms.

\section{STEM to STEAM}

STEM is the acronym for Science, Technology, Engineering and Mathematics, used by authors worldwide in their research contributions for specialized journals (e.g., https://stemeducationjournal.springeropen.com/). Currently, there is a move towards including art to STEM disciplines (http://stemtosteam.org/), and for STEM projects to become STEAM projects.

"Muthsics" is the intentional combination of "mu-sic" and "(ma)th-s". Music and mathematics complement each other, as both disciplines contribute with their unique characteristics. Our postulate is that muthsics projects are a proper context for developing STEAM principles.

The problem lies in how to bring these creative experiences to schools and make them compatible with the established curriculum? How can we involve teachers without advanced studies in mathematics or in music, or those with monolithic training in one of the disciplines? Under what conditions is it possible to propose these projects in a controlled and evaluable manner for schools?

\section{Experimentation}

\subsection{Mathematical and Musical Content}

We will begin with a brief description of the mathematical content included and how the musical rhythms were employed to enhance the teaching of mathematics [1, 4]. The subjects included can be grouped into three general categories as follows: 
(1) Euclid's Lemma and Euclid's algorithm, maximal evenness, and Euclidean rhythms.

(2) Clapping Music and cyclic permutations [3].

(3) Euclidean rhythms and mathematical calculations such as the greatest common divisor of two natural numbers. In terms of rhythm, it has been seen that the most common world rhythms are Euclidean rhythms [4].

In the mathematical context, there is growing interest for the incorporation of automatized procedures that mimic classical calculations ("maths by computer"). This perspective covers the learning stages at all levels, not only the university. According to the NCTM (http://www.nctm.org), technology determines, whether we like it or not, not only how to teach, but what to teach [2].

\subsection{Context and sample}

Candidates for teaching at the middle and high School levels (12-20 years old) in Spain should pursue a Master's Degree in Teaching at the Secondary Level, which is a professional requisite. The applicants to the Master's program must have a Bachelor's Degree and the students who opt for the specialization in Mathematics come from different backgrounds. In table 1, we show the student distribution by backgrounds and sex.

Table 1. Student distribution by backgrounds and sex.

\begin{tabular}{cc|cc|ccccc}
\hline School year & Total & W & M & Engin & Archi & Maths & Phys & Eco \\
\hline 1st & 6 & 4 & 2 & 4 & 1 & --- & --- & 1 \\
2nd & 7 & 4 & 3 & 4 & 1 & 1 & 1 & --- \\
\hline
\end{tabular}

Key: W: Women; M: Men; Engin: Engineering; Archi: Architecture;

Maths: Mathematics; Phys: Physics; Eco: Economics

\subsection{Instruments, premises and objectives}

Before carrying out the activities the students answered a brief survey about their musical training. It can be said that the students had solid scientific-technical training, but little musical training; in this area, they were inexpert (muthsics for clueless). For this reason, we needed to teach musical terms (time span, pulses, notes, rests, rhythm, piece, etc.) before carrying out the actual activities relating music to mathematics.

The activities were distributed in two sessions of 1 hour 45 minutes each, and alternated individual answers to proposed tasks with the collective discussion of their musical and mathematical content, as well as their relation to the school curriculum and the present tendencies concerning Secondary Education students and how they can acquire the knowledge and the skills mandated in the general program requirements. Due to space limitations, we will focus on activities 5 and 8 in session 1:

- S1.5 (5 min). The time period is divided in 12 pulses. It represents a rhythm as "even" as possible, with 4 notes $(\bullet)$ and 8 rests $(-)$. The students produced rhythms of 12 pulses ( 4 notes and 8 rests). They were given a grid to facilitate an empirical search of flamenco rhythms (fandango, soleá, etc.). (figure 1). 


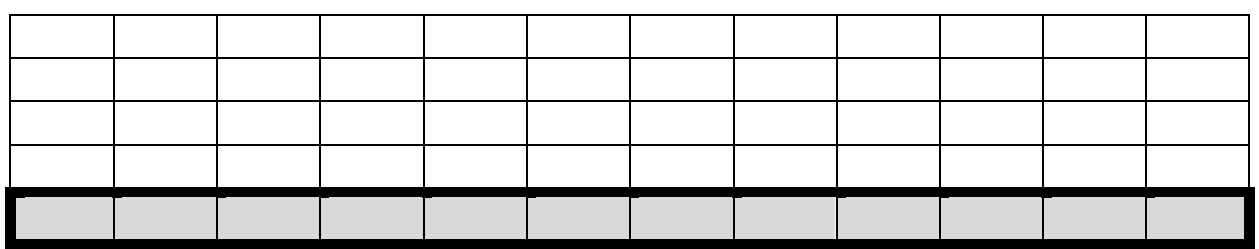

Figure 1. Search for rhythms.

- $\mathrm{S} 1.8(10 \mathrm{~min})$. The time period is divided in 12 pulses. It represents a rhythm as "even" as possible, with 8 notes $(\bullet)$ and 4 rests $(-)$ Once you have found a rhythm, try to show one that preserves regularity ("evenness"). The students, "on the march", were to apply the notion of "evenness". It was assumed that they would use musical or technical criteria, but that mathematical knowledge would not play a role in the activity, that is, they would not search for an algorithm based on the principles of maximal evenness and Euclid's algorithm.

\section{$3 \quad$ Results and Discussion}

The proposed rhythms are formed by a longitudinal characteristic (the repetition of a pattern) or by symmetry with respect to the center (6 pulses "to the left" y 6 pulses "to the right"). In Table 3 all the proposed rhythms are shown.

Table 3. Rhythms proposed by the students, as "even as possible" (4 notes, $\bullet ; 8$ rest, - ).

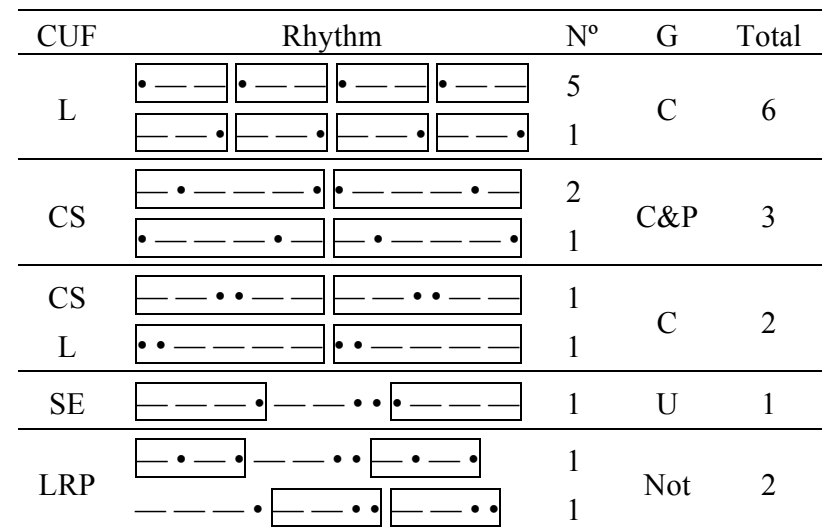

CUF: Characteristic used in forming. L: Longitudinal; CS: Central Symmetry; SE: Symmetry at the extremes; LRP: Longitudinal, with a maximum of repeated patterns

G: Grouping; C: Circular; P: Permutation; U: Unique; Not: Does not respond to the proposed rhythm

In situation 8 , where they must represent an "even" rhythm with 8 notes $(\bullet)$ y 4 rests (-), the students contributed 28 timelines. Half of them (14 out of 28$)$ are ob- 
tained by a repetition of the pattern that contains two notes and a rest $(\bullet-/,-\bullet / \bullet$ - $)$ ) or combinations of these three patterns. This type of timeline is produced by 9 of the 14 students. On the other hand, 5 of 28 patterns are repetitions or combinations of the two patterns that contain four notes and two rests $(\bullet \bullet-\ldots \ldots / \ldots$ justification of the proposed "even" rhythms is not anecdotal. Several students make notes in the margins or the back of their notepaper that refer to the symmetry ("making groups, by symmetry, because they are in pairs") or groupings by divisibility.

Through the activity, the students come to realize that mathematics can model musical patterns and that this leads to different types of music (circular permutations) in a much more efficient manner than the trial and error method. Likewise, they see that "known" mathematical techniques (calculation of the GCD) in a specific context (arithmetic, by factorization) has not been easily extrapolated to an extra mathematical context. This supposes a very deep learning experience in terms of what "learning mathematics" and "using mathematics" means.

\section{In conclusion}

Muthsics is not a mere metaphor or play on words; it is a proposal for specific teaching and learning situations around mathematics and music that will allow students to learn new concepts in both areas by starting from their previous formal knowledge. The situations should allow the integration of the creative experience with the demands of the curriculum, even bettering the usual delivery of the disciplines. It is also essential that teachers without advanced training in mathematics or music, and whose focus is just one of the areas, are able to propose muthsics projects that can be controlled and evaluated.

Acknowledgement: This research work has been carried out within the framework of the project EDU2017-84979-R, of the Spanish State Program of R\&D and Innovation Oriented to the Challenges of the Society.

\section{References}

1. Demaine, E., Gómez, F., Meijer, H., Rappaport, D., Taslakian, P., Toussaint, G. T., Winograd, T. and Wood, D. R., (2009). The Distance Geometry of Music, Computational Geometry: Theory and Application, 42, pp. 429-454.

2. NCTM (2017). Executive Summary: Principles and Standards for School Mathematics. Reston, VA: Autor.

3. Reich, S. (1972). Clapping Music for two performers. [Retrieved 2017/12/01: http://earreader.nl/wp-content/uploads/2016/01/SteveReich-ClappingMusic.pdf]

4. Toussaint, G. (2013). The Geometry of Musical Rhythm. Chapman and Hall/CRC, London.

5. Wilhelmi, M. and Montiel, M. (2018) Muthsics for Clueless: An Experiment with Euclidean Rhythms in Theoretical and Practical Pedagogy of Mathematical Music Theory: Music for Mathematics and Mathematics for Musicians, From School to Postgraduate Levels, eds. M. Montiel and F. Gómez, World Scientific Publishing Co. 